\title{
Corrosion Behavior of Stainless Steel 304, Titanium, Nickel and Aluminium in Non-Aqueous Electrolytes
}

\author{
Bonita Dilasari ${ }^{1}$, Jesik Park ${ }^{2}$, Priyandi Kusumah ${ }^{1}$, Kyungjung Kwon ${ }^{1, *}$, and Churl Kyoung Lee ${ }^{2, *}$ \\ ${ }^{1}$ Department of Energy \& Mineral Resources Engineering, Sejong University, Seoul 143-747, Korea \\ ${ }^{2}$ School of Advanced Materials \& Systems Engineering, Kumoh National Institute of Technology, Gumi, \\ Gyungsangbuk-do 730-701, Korea
}

(Received December 5, 2013 : Accepted January 3, 2014)

\begin{abstract}
The corrosion behavior of stainless steel 304 (SS 304), titanium, nickel and aluminium is studied by immersion and anodic polarization tests in non-aqueous electrolytes. Tetraethyl ammonium tetrafluoroborate is used as a supporting electrolyte in the three kinds of solvents. The immersion test shows that chemical corrosion rate in propylene carbonate-based electrolyte is lower than those in acetonitrile- or $\gamma$-butyrolactone-based electrolytes. Surface analyses do not reveal any corrosion product formed after the immersion test. In the anodic polarization tests, a higher concentration of supporting electrolyte gives a higher current density. In addition, a higher temperature increases the current density in the active region and reduces the potential range in the passive region. SS 304 shows the highest corrosion potential while $\mathrm{Al}$ shows the lowest corrosion potential and the highest current density in all studied conditions. Based on the conducted corrosion tests, the corrosion resistance of metal substrates in the organic solvents can be sorted in descending order as follows: SS $304-\mathrm{Ti}-\mathrm{Ni}-\mathrm{Al}$.
\end{abstract}

Keywords : Corrosion test, non-aqueous electrolyte, stainless steel, titanium, nickel, aluminium

\section{Introduction}

Since the utilization of non-aqueous electrolytes in battery application such as lithium-ion batteries is essential, the corrosion resistance of metals in non-aqueous electrolytes is of tremendous importance. It is known that passivation mechanisms in non-aqueous electrolytes are different from common aqueous electrolytes. Since oxide/ hydroxide film formation is unlikely to occur in non-aqueous electrolytes, there are three possible mechanisms for metal to passivate in non-aqueous electrolytes, which are by air-formed film protection, salt film formation, or chemisorption of the solvent. ${ }^{1)}$ Corrosion behavior in nonaqueous electrolytes depends on the type of metal and organic solvent. For stainless steel 304 (SS 304), airformed film is protectively stable up to the oxidation potential of the solvent in an anhydrous propylene carbonate (PC) solvent containing lithium salts. $\left.{ }^{2}\right)$ Trasatti et al. ${ }^{3)}$

*E-mail: kfromberk@gmail.com (K. Kwon) cklee@kumoh.ac.kr (C.K. Lee) concluded the corrosion of $\mathrm{Ti}$ in an organic solvent is initiated with rupture or thinning of the surface film followed by reactions between $\mathrm{Ti}$ and organic species, and the final removal of corrosion products from the metal surface.

SS 304, Ti, Ni and Al are common metals used as current collectors and casing materials in lithium-ion battery, as well as electrodes and bipolar plates in redox flow battery (RFB). ${ }^{4-9)}$ To our knowledge, the corrosion behavior of these metals in non-aqueous electrolytes has not been systematically investigated so far. A thorough study on metal corrosion in commonly used organic solvents would support the development of non-aqueous battery technology. Therefore, this study is aimed to provide a basic corrosion evaluation of SS 304, Ti, Ni and $\mathrm{Al}$ to help understanding the metal corrosion phenomena in non-aqueous electrolytes.

\section{Experimental}

Metals investigated in this study were commercially available SS 304, Ti, Ni and Al. An immersion test was 
carried out to study the corrosion behavior of each metal in an electrolyte based on three different solvents, which were propylene carbonate $\left(\mathrm{PC}, \mathrm{C}_{4} \mathrm{H}_{6} \mathrm{O}_{3}\right)$, acetonitrile (AN, $\mathrm{C}_{2} \mathrm{H}_{3} \mathrm{~N}$ ) and $\gamma$-butyrolactone $\left(\mathrm{GBL}, \mathrm{C}_{4} \mathrm{H}_{6} \mathrm{O}_{2}\right)$. A supporting electrolyte, tetraethyl ammonium tetrafluoroborate $\left(\mathrm{TEABF}_{4}\right)$, was added to each solvent. Metal specimens were immersed in $0.1 \mathrm{M} \mathrm{TEABF}_{4}$ dissolved in the solvents at $30^{\circ} \mathrm{C}$ for $24 \mathrm{~h}$ and then a weight loss of the specimens was measured and converted to a chemical corrosion rate. Sheet resistance of metal specimens was measured by 4-point probe (Bio-Rad HL5500PC) before and after the immersion test. Field emission scanning electron microscope (FE-SEM, JEOL JSM$6500 \mathrm{~F}$ ) and X-ray diffraction (XRD, D/MAX-2500) analyses were conducted on the specimen surface before and after the immersion test.

The effects of $\mathrm{TEABF}_{4}$ concentration and temperature on the corrosion resistance of each metal were evaluated by anodic polarization measurements. ${ }^{10,11)}$ The anodic polarization measurements used a three-electrode system composed of a tested metal as a working electrode, platinum mesh as a counter electrode and $\mathrm{Ag} /$ $\mathrm{Ag}^{+}$as a reference electrode. All potentials in this paper are reported on ferrocene/ferricenium $\left(\mathrm{Fc} / \mathrm{Fc}^{+}\right)$basis after calibration with the $\mathrm{Ag} / \mathrm{Ag}^{+}$electrode. The anodic polarization measurements were conducted in a potentiodynamic mode in the potential range of -0.5 to $1.5 \mathrm{~V}$ at a scan rate of $3 \mathrm{mV} / \mathrm{s}$. The anodic polarization measurements with a variation in supporting electrolyte concentration were carried out in a PC solvent containing 0.001 and $1 \mathrm{M} \mathrm{TEABF}_{4}$ at room temperature. In addition, the temperature was increased from room temperature to $60^{\circ} \mathrm{C}$ to study the temperature effect on the corrosion rate of each metal in the $\mathrm{PC}$ solvent containing $1 \mathrm{M} \mathrm{TEABF}_{4}$.

\section{Results and Discussion}

\subsection{Immersion test}

Corrosion rates obtained from the immersion test in each solvent are presented in Fig. 1. According to the result, the solvent order from the most corrosive one is as follows: GBL $>$ AN $>$ PC. We observed that all metal specimens show the lowest corrosion rate in the PC solvent, which can be attributed to its lowest conductivity among the three kinds of solvents. Generally, a less conductive electrolyte is less corrosive to metals as we con-

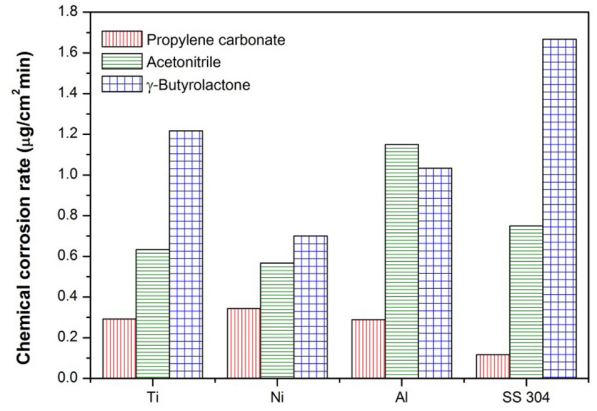

Fig. 1. Chemical corrosion rate obtained from the immersion test with $1 \mathrm{M} \mathrm{TEABF}_{4}$ in PC, AN and GBL.

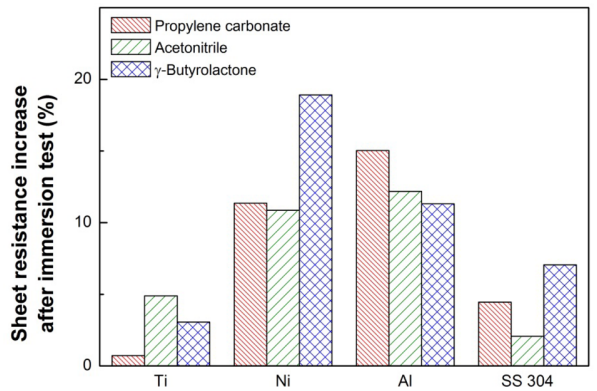

Fig. 2 Sheet resistance increase after the immersion test with $1 \mathrm{M} \mathrm{TEABF}_{4}$ in PC, AN and GBL.

firmed that the conductivity of $\mathrm{PC}$ containing $1 \mathrm{M}$ $\mathrm{TEABF}_{4}$ has the lowest among the three kinds of solvents. This is in accordance with the earlier study by Palanisamy et al., ${ }^{12)}$ who found that the conductivity of $\mathrm{PC}+1 \mathrm{M} \mathrm{TEABF}_{4}$ electrolyte is lower than those of $\mathrm{AN}-$ and GBL-based electrolytes.

An increase in sheet resistance after the immersion test is displayed in Fig. 2. The resistance increases of $\mathrm{Ti}$ and SS 304 are below 10\%, less than $\mathrm{Ni}$ and $\mathrm{Al}$. Ti shows the smallest increase only by about $0.7 \%$ after the immersion test in $\mathrm{PC}+1 \mathrm{M} \mathrm{TEABF}$. The negligible increase in sheet resistance indicates that there is no corrosion product formed on the metal surface after the immersion test. The relatively large increase in sheet resistance on $\mathrm{Ni}$ specimen could be attributed to the formation of a protective passive film on Ni surface even with the existence of a trace amount of water in the electrolyte. ${ }^{13)}$ SEM images and XRD patterns before and after the immersion test in $\mathrm{PC}+1 \mathrm{M} \mathrm{TEABF}_{4}$ are exhibited in Fig. 3. Surface morphology and XRD patterns of all specimens do not show any significant 

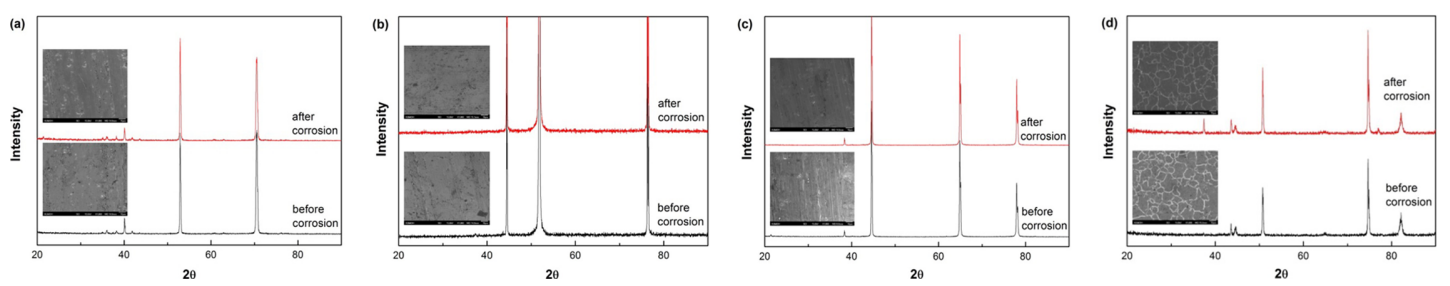

Fig. 3. SEM images and XRD patterns on (a) Ti, (b) Ni, (c) Al and (d) SS 304 before and after the immersion test with $1 \mathrm{M} \mathrm{TEABF}_{4}$ in PC.

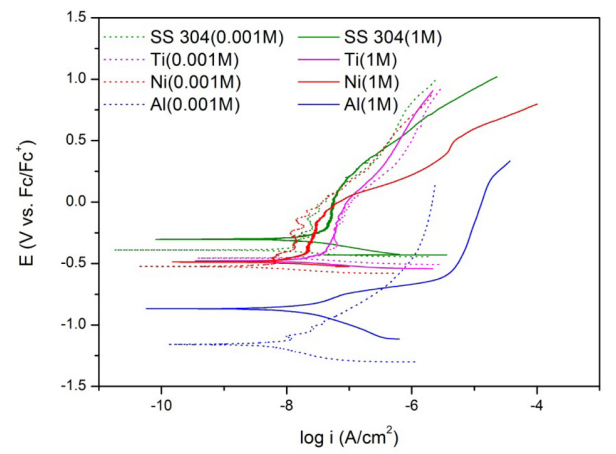

Fig. 4 Anodic polarization curves with $0.001 \mathrm{M}$ or $1 \mathrm{M}$ $\mathrm{TEABF}_{4}$ in $\mathrm{PC}$.

change before and after the immersion test. Even though $\mathrm{Ni}$ and $\mathrm{Al}$ undergo relatively larger resistance increases, no significant change was identified by the surface analyses, which makes it difficult to verify the aforementioned possibility of forming a protective passive film.

\subsection{Anodic polarization test}

The anodic polarization tests were conducted in PCbased electrolytes because the immersion tests showed the lowest chemical corrosion rates of all metal specimens in PC-based electrolytes. Fig. 4 displays the polarization curves in PC containing 0.001 and $1 \mathrm{M}$ concentration of the supporting electrolyte. A higher concentration of the supporting electrolyte is supposed to give a higher conductivity. Therefore, a higher current density is observed on the polarization curves of $1 \mathrm{M} \mathrm{TEABF}_{4}$ with the exception of Ti, of which current densities do not seem to be affected by the TEABF 4 concentration. $\mathrm{Al}$ shows the lowest corrosion potential while SS 304 shows the highest one with both supporting electrolyte concentrations. Al also encounters the highest dissolution rate as shown by the immediate

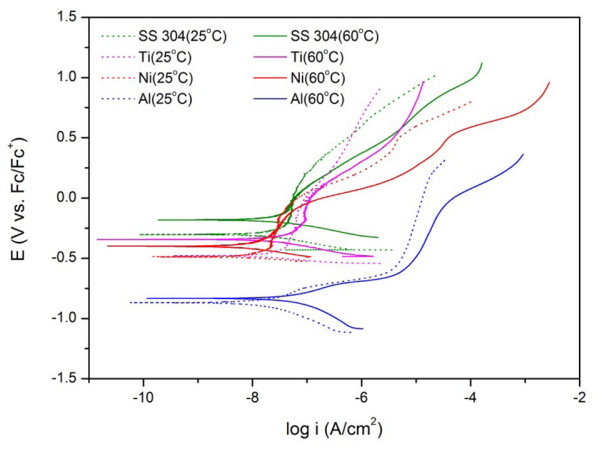

Fig. 5 Anodic polarization curves at 25 and $60^{\circ} \mathrm{C}$ with $1 \mathrm{M} \mathrm{TEABF}_{4}$ in PC.

increase in current density in the anodic scan from the corrosion potential. In contrast, $\mathrm{Ti}, \mathrm{Ni}$ and $\mathrm{SS} 304$ show a certain passive region before a rapid increase in current density develops. Fig. 5 shows the polarization curves at 25 and $60^{\circ} \mathrm{C}$ in $\mathrm{PC}+1 \mathrm{M} \mathrm{TEABF}_{4}$ electrolyte. It is obvious that a higher temperature gives a higher current density in the active region and gives a narrower passive region. This is because an increase in temperature can enhance ion mobility that accelerates reaction kinetics and passive film breakdown. Therefore, the use of these non-aqueous electrolytes in high temperature applications would need a careful consideration of metal corrosion issue with an increase in temperature.

\section{Conclusions}

The immersion test revealed that PC is the less corrosive solvent to the four kinds of metals (SS 304, Ti, Ni and $\mathrm{Al}$ ) than $\mathrm{AN}$ and GBL. Sheet resistance measurements showed that the average resistance increase after the immersion test was quite high for $\mathrm{Ni}$ and $\mathrm{Al}$ in the range of 10 to $20 \%$. The anodic polarization test showed that a higher $\mathrm{TEABF}_{4}$ concentration gives a higher cur- 
rent density. In addition, a higher temperature increases the current density in the active region and reduces the potential range of the passive region. In all studied conditions, SS 304 showed the highest corrosion potential while Al exhibited the lowest corrosion potential and the highest current density. Overall, SS 304 displayed a superior performance, and $\mathrm{Ti}$ also seemed satisfactory in PC-based electrolytes compared to the other specimens as seen by the stable behavior during the immersion and polarization tests. Based on the conducted corrosion tests, the corrosion resistance of metal substrates in the organic solvents can be sorted in descending order as follows: SS 304 - Ti - Ni - Al.

\section{Acknowledgements}

This work was supported by the Energy Efficiency \& Resources of the Korea Institute of Energy Technology Evaluation and Planning (KETEP) grant funded by the Korea government Ministry of Knowledge Economy (No. 2009T100200074).

\section{References}

1. R. G. Kelly and P. J Moran, 'The passivity of metals in organic solutions' Corr. Science, 30, 495 (1990).

2. D. A. Shifler, P. J. Moran and J. Kruger, 'The passivity of 304 stainless steel in propylene carbonate solutions' $J$. Electrochem. Soc., 139, 54 (1992).

3. E. P. Trasatti and E. Sivieri, 'Corrosion behaviour of titanium in non-aqueous solvents' Mater. Chem. Phys., 92, 475 (2005).

4. C. Iwakura, Y. Fukumoto, H. Inoue, S. Ohashi, S. Kobayashi, H. Tada and M. Abe, 'Electrochemical character- ization of various metal foils as a current collector of positive electrode for rechargeable lithium batteries' $J$. Power Sources, 68, 301 (1997).

5. T. K. Kim, W. Chen and C. Wang, 'Heat treatment effect of the Ni foam current collector in lithium ion batteries, J. Power Sources, 196, 8742 (2011).

6. S. T. Myung, Y. Sasaki, S. Sakurada, Y. K Sun and H. Yashiro, 'Electrochemical behavior of current collectors for lithium batteries in non-aqueous alkyl carbonate solution and surface analysis by ToF-SIMS' Electrochim. Acta, 55, 288 (2009).

7. E. Cho, J. Mun, O. B. Chae, O. M. Kwon, H. T. Kim, J. H. Ryu, Y. G. Kim and S. M. Oh, 'Corrosion/passivation of aluminum current collector in bis(fluorosulfonyl)imide-based ionic liquid for lithium-ion batteries' Electrochem. Commun., 22, 1 (2012).

8. Y. Wang, H. Liao, J. Wang, X. Qian, Y. Zhu and S. Cheng, 'Effects of current collectors on electrochemical performance of $\mathrm{FeS}_{2}$ for Li-ion battery' Int. J. Electrochem. Sci., 8, 4002 (2013).

9. J. H. Kim, K. J. Kim, M. S. Park, N. J. Lee, U. Hwang, H. Kim and Y. J. Kim, 'Development of metal-based electrodes for non-aqueous redox flow batteries' Electrochem. Commun., 13, 997 (2011).

10. Korean Standard KS D 0279, 'Standard practice for conventions applicable to electrochemical measurements in corrosion testing' (2005).

11. ASTM Standard G 5-94, 'Standard reference test methods for making potentiostatic and potentiodynamic anodic polarization measurements' ASTM International, (2011).

12. G. Palanisamy, S. E. LaCroix, A. A. S. Siggel and M. Fooken, 'Non aqueous electrolyte' U.S. Patent, US 20050014070A1 (2005).

13. T. Fujieda, S. Koike and S. Higuchi, 'Influence of water and other contaminants in electrolyte solutions on lithium electrodeposition' MRS Proceedings, 496, 463 (1997). 